Article

\title{
Children's Psychological Representation of Earthquakes: Analysis of Written Definitions and Rasch Scaling
}

\author{
Daniela Raccanello *(D), Giada Vicentini and Roberto Burro \\ Department of Human Sciences, University of Verona, 37129 Verona, Italy; giada.vicentini@univr.it (G.V.); \\ roberto.burro@univr.it (R.B.) \\ * Correspondence: daniela.raccanello@univr.it; Tel.: +39-045-802-8157
}

Received: 19 April 2019; Accepted: 7 May 2019; Published: 9 May 2019

check for updates

\begin{abstract}
Natural disasters have a potential highly traumatic impact on psychological functioning. This is notably true for children, whose vulnerability depends on their level of cognitive and emotional development. Before formal schooling, children possess all the basic abilities to represent the phenomena of the world, including natural disasters. However, scarce attention has been paid to children's representation of earthquakes, notwithstanding its relevance for risk awareness and for the efficacy of prevention programs. We examined children's representation of earthquakes using different methodologies. One hundred and twenty-eight second- and fourth-graders completed a written definition task and an online recognition task, analyzed through the Rasch model. Findings from both tasks indicated that, in children's representation, natural elements such as geological ones were the most salient, followed by man-made elements, and then by person-related elements. Older children revealed a more complex representation of earthquakes, and this was detected through the online recognition task. The results are discussed taking into account their theoretical and applied relevance. Beyond advancing knowledge of the development of the representation of earthquakes, they also inform on strengths and limitations of different methodologies. Both aspects are key resources to develop prevention programs for fostering preparedness to natural disasters and emotional prevention.
\end{abstract}

Keywords: psychological representation of earthquakes; open-ended and closed-questions surveys; children; seismic hazard assessment; emotions; emotional prevention

\section{Introduction}

This study focuses on children's psychological representation of natural disasters such as earthquakes. Knowledge of individuals' - and in particular children's-representation of earthquakes is highly relevant from both a theoretical and an applied perspective. From a theoretical perspective, it provides information on how people develop complex representations of risk-related phenomena, revealing which are the most salient elements when people perceive them; this is also key information when studying risk awareness, e.g., [1]. From an applied perspective, awareness of children's knowledge of earthquakes is a preliminary step for prevention programs, aiming at promoting the mastery of adequate geological, behavioral, and psychological contents, also after the identification of lacking areas. However, scarce attention has been devoted to study how children develop concepts and representations of natural disasters.

Nowadays, these issues are increasingly important, in light of both the prevalence of seismic events and the higher exposure to them through all the mass media and social networks [2,3]. In other words, it is currently more probable for a child to become a direct or indirect victim of an earthquake than in the past. 
From a psychological perspective, natural hazards, including earthquakes, have a potentially highly traumatic impact on individuals' functioning [4-6]. Documented traumatic consequences include impaired health (e.g., cardiovascular ailments, etc.), increased rates of psychopathology (e.g., posttraumatic stress disorder, distress, depression, etc.), and negative emotional impact (e.g., anxiety, fear, anger, feelings of threat, etc.), both for primary victims experiencing the events directly and for secondary victims indirectly affected through media exposure, e.g., [7-10]. This is notably true for children and adolescents, whose vulnerability depends on their level of cognitive and emotional development [11].

The aim of this study is to fill in a gap in the literature, investigating how children develop the representation of earthquakes using two different tasks, a written definition task and an online recognition task.

\subsection{Children's Abilities to Represent the World}

Before formal schooling, children spontaneously develop naïve physics, biology, and psychology theories on the world, enabling them to make differentiations between domains and also to draw connections between them [12-16]. Naïve theories include elements on both the nature of the phenomena, i.e., ontological elements, and their underlying causal mechanisms and interrelations [12-16].

With regard to the physical domain, the grasping of core beliefs about the nature of physical objects and physical causes begins in infancy, and a deeper comprehension develops gradually later on [14]. Such everyday understanding is central for the development of people's interaction with any middle-sized object present in the external world.

Concerning the biological domain, authors such as Carey [17] credit children with a naïve theory of biology from seven or eight years. Previously, they would accumulate encyclopedic knowledge of biological events, which would undergo a conceptual change only later on. However, other authors have suggested that preschool children also possess a biological theory distinct from a psychological theory $[14,18,19]$. This is indicated for example by their abilities to attribute the causes of phenomena such as illnesses to the contact with contaminated substances rather than to psychological reasons [19].

Finally, children begin to develop a psychological theory, or theory of mind, from an early age, interacting with the social environment $[20,21]$. Preschool children understand both ontological aspects and related causal processes [21-23]. Ontological elements of the psychological theory relate to the existence and nature of mental states which are different from the real world of physical objects, material states, and mechanic or behavioral processes. Psychological causality regards the understanding of the relation between internal states, such as affects or cognitions, and one's own or others' overt behaviors [21].

Therefore, primary school students do possess all the basic abilities to represent the world, included natural phenomena such as earthquakes. Nevertheless, possible wrong ideas included in their spontaneous representation of the world should be detected before formal school instruction, in order to optimize the outcomes of learning processes.

\subsection{Knowledge of Children's Representation of Earthquakes}

As regards specifically natural disasters such as earthquakes, only a few studies investigated children's representation of them, focusing more on factual knowledge rather than psychological knowledge [24-27].

For example, Ross and Shuell involved New Zealander kindergartners through to sixth-graders with different experience of earthquakes, and found that a scientific conceptualization of them was rare, even if they revealed a certain awareness of their causes and consequences [27]. Similar results emerged with a sample of Turkish first- to sixth-graders [25]. However, more recent findings with New Zealander nine- and ten-year-olds suggested that children are quite aware of the core characteristic of earthquakes [24]. Raccanello and colleagues [26] revealed that second- and fifth-graders demonstrate a more refined representation of earthquakes in case they had experienced them directly and at 
increasing ages, without gender differences [26]. Specifically, higher refinement was described in terms of a more complex knowledge, a more frequent use of emotional language, and the presence of more intense emotions relating to earthquakes.

Studying how people, and in particular children, perceive and represent natural disasters could help to improve their risk awareness in order to promote an adequate preparedness [1], in particular focusing on emotional prevention [28]. However, on the whole, scarce attention has been paid to examining children's representation of earthquakes.

\subsection{Some Methodologies to Investigate Children's Representation of Earthquakes}

When investigated, children's representation of earthquakes has been studied with exploratory methodologies such as interviews or focus groups, frequently including open-ended questions [24-27]. King and Tarrant [24] involved nine- and ten-year-olds in focus groups. Laçin Şimşek [25] used semi-structured interviews with open-ended questions with first- to sixth-graders. Raccanello and colleagues [26] investigated primary school children's representation of earthquakes by analyzing the content of oral definitions elicited individually. Self-report tasks such these have the great advantage of enabling direct access to people's inner states, and notwithstanding possible bias effects such as social desirability they are still among the privileged ways to explore people's representation of one phenomenon [29]. However, they are time consuming in terms of transcription and coding of the materials. Moreover, individual interviews make it possible to gather detailed data on single participants, but they cannot be used collectively, and on the contrary focus groups can be used collectively but do not give the possibility to have data enabling to examine individual differences. In addition, such tasks rely on production abilities that give the responders the possibility to use their own lexicon without constriction, e.g., [30-33]. Indeed, a great advantage of open-ended questions consists in the variety of nuances emerging from the answers, useful in exploratory studies and impossible to observe when using closed questions. Nevertheless, they are quite demanding in terms of cognitive resources, especially for children.

An alternative way of exploring children's definitions of earthquakes is to use written tasks. Such tasks can be administered collectively, saving time, a requisite which can be fully appreciated when considering the need for involving a large number of people within prevention programs. Moreover, they enable to investigate individual differences. It is worth noting that, particularly for primary school children, performance in written tasks strictly depends on their emerging literacy abilities. Therefore, it is interesting to explore whether earthquakes' representation of children who have just acquired basic writing abilities emerges as similar when studying oral versus written definitions. This issue has been neglected within the literature as yet.

In addition, both oral and written definition tasks still rely on production abilities, which are mastered later during development compared to recognition abilities. This is the case, for example, with what happens for language at early ages [34]. Frequently, data gathered with oral or written production tasks are operationalized in order to obtain a description of the phenomenon at issue in terms of frequency tables corresponding to coding categories, which are usually treated as linear measures [35-40]. Such a process risks to distort the results. Alternatively, a way to investigate children's representation of earthquakes could be through recognition tasks, in which for example children have to evaluate how much a set of presented stimuli conveys the concept of earthquake. Data gathered through these kinds of tasks can be analyzed through the Rasch model [41-43], which makes it possible to go beyond the cited distortions, producing proper linear measures. In particular, the Rasch model goes beyond the weak points of traditional approaches to measurement (i.e., the classic test theory) by giving priority to objective measurement of latent dimensions which are based on the principles of fundamental measurement [44]. In other words, the characteristics of the individuals are measured independently of the characteristics of the stimuli (or items) and the stimuli calibrations is independent from the characteristics of the individuals. Fundamental measurement is taken for granted in the physical sciences, whereas in the social sciences the raw scores and the sum or means 
of these scores are typically considered as measures of a dimension independently of whether or not they conform to the principles of fundamental measurement [45]. However, also within the psychological field this approach can be used to investigate how people represent characteristics of the world, quantifying them, e.g., [46-50]. In particular, a specific advantage of the Rasch model is the "conjoint measurement" [35]: It is possible to estimate the values for persons and stimuli that can be represented on the same interval-scale of latent units (logits). The logits of persons (i.e., person-location) are independent from the administered stimuli (test-free condition) and the logits of stimuli (i.e., stimulus-location) are independent from the persons (sample-free condition). The accuracy of Rasch scaling is quantifiable by means of precise fit statistics [51].

Finally, individuals' representation of earthquakes could be studied taking advantage of what is offered by information and communication technology (ICT). Nowadays, the use of technologies for assessing how individuals perceive, elaborate, and react in everyday life, also in relation to learning, is increasing [10,52-55]. Given the growth in technological developments, psychological constructs can therefore be assessed and also promoted through many different devices (personal computers, laptops, tablets, mobile phones, etc.). Such use has many advantages. One advantage is the assessment mode, i.e., the self-administration in absence of a data collector [56]. Another is the fact that the individuals may tend to give more socially desirable responses in interviewers' administration than in self-administration [57]. Moreover, with ICT instruments there is the possibility, differently from what happens in laboratory studies, to assess the construct of interest within the individual's environment, increasing ecological validity [58]. A further advantage in using technological devices such as personal computers, tablets, or mobile phones to collect data in psychological research studies seems to be connected with higher and easier participation [59]. Even if the use of ICT within the psychological field is becoming more and more frequent, the current state of knowledge about the dynamics of taking surveys or teaching through learning software or applications is not as advanced as necessary, and more scientific literature is needed to evaluate some methodological aspects. Specifically, scarce attention has been paid to examining, for example, the appropriateness of materials and procedures for users' characteristics such as age, developing applications (as an exception, see the Emotional Prevention and Earthquakes in primary school project, PrEmT project, in Italian Prevenzione Emotiva e Terremoti nella scuola primaria, in which a web application on earthquake-related emotions for children is developed) [28]; the use of reliable research design to investigate the efficacy of interventions using ICT (i.e., evidence-based interventions) [28,60,61]; or the perception on usability of people involved in online psychological surveys, with children, e.g., [62] or adults, e.g., [28]. Therefore, further research on such issues is needed, in order to develop online instruments which can accurately detect individuals' characteristics and representation of the world, and subsequent programs aiming to enhance them.

\subsection{Aims and Objectives of the Present Study}

The general aim was to investigate children's representation of earthquakes, generalizing previous findings using different tasks [26]. Previous work indicated that when second and fifth-graders were requested to define earthquakes orally [26], they demonstrated a more complex representation in cases where they had experienced earthquakes directly and at increasing ages, without gender differences. Specifically, the salience of content categories pertaining to the material domain, such as natural and man-made elements, was higher compared to the salience of content categories relating to the person-related domain, such as behavioral, biological, or affective elements. Children with direct experience of earthquakes also referred more frequently to natural compared to man-made elements. In addition, at increasing ages, children reported definitions with more differentiated content types.

Beyond its theoretical relevance, knowledge of how different instruments enable to gather children's representation of earthquakes, with their strength, differences, and limitations, is relevant at an applied level. For example, this is a key element when choosing the more suitable instruments to increase awareness on children's representation as a preliminary step for intervention programs, both in terms of prevention and support subsequent to natural disasters. 
For the written definition task, we had two objectives.

(1a) The first objective was to examine the salience of different domains in children's representation of earthquakes. On the basis of previous findings [26], we expected salience to be higher for natural elements compared to man-made elements, and for man-made elements compared to human elements.

(1b) The second objective was to examine whether the salience of the different domains varied according to age and gender. Concerning age, we hypothesized children to refer more frequently to the different domains at increasing ages [26]. Given the absence of gender differences in the literature, we did not formulate any specific hypothesis for gender.

Also, for the online recognition task, we had two objectives.

(2a) The first objective was to develop some images representing earthquakes and to quantify how much each of them conveyed the concept of earthquake $[47,48]$. In particular, we aimed at identifying the characteristics of the most representative images in terms of domains. Scales including such images as stimuli could be used as measurement instruments to assess how an earthquake is perceived.

(2b) The second objective was to examine how much children are able to perceive an earthquake on the basis of given stimuli. Specifically, we investigated age and gender differences. We expected children to be better able to identify earthquake-related stimuli as representing an earthquake at increasing ages, in parallel with better abilities to define earthquakes [26]. As for the written definition task, we did not have any specific hypothesis for gender.

\section{Materials and Methods}

\subsection{Participants}

We involved a convenience sample of 128 Italian primary school children. Sixty-three children were attending the second grade (mean age: 7.53 years, $S D=0.34 ; 43 \%$ females) while 65 were attending the fourth grade (mean age: 9.63 years, $S D=0.25 ; 54 \%$ females). For each grade level, the students were divided into four classes. The participants came from a variety of socio-economic status levels. We collected the data during February 2019 in Northeastern Italy.

Most of the children had never experienced earthquakes directly $(n=91 ; 71 \%)$ and only a small percentage of children had experienced them $(n=30 ; 23 \%)$. For seven children $(6 \%)$ this information was missing. Among children who experienced earthquakes at least once, 19 children (64\%) experienced one earthquake; 10 children (33\%) experienced earthquakes twice; and one child (3\%) experienced earthquakes three times. None of the children who had experienced earthquakes at least once reported any damage.

\subsection{Procedure}

The study was carried out following American Psychology Association (APA) ethical guidelines, and it was approved by the Local Ethical Committee of the Department of Human Science, University of Verona (protocol n. 134535) as part of a larger project, the PrEmT project [28]. The PrEmT project has the objective to test an intervention to promote children's knowledge of earthquakes and earthquake-related emotions, through an evidence-based design. The sample included in this study was involved in the pre-intervention phase of the pilot phase of the PrEmT project. Therefore, the students had not been involved previously in activities related to this project. In addition, we had verified with the teachers that they had not studied specific knowledge of earthquakes within their school lessons.

We obtained the authorization for the participation of children first from the school head, and then we obtained the informed written consents from parents.

We administered two tasks in class during regular school hours, in two sessions maximum one week apart one from the other. The school teachers were present, but they did not intervene. For both tasks, we read all the instructions aloud, in order to help children's understanding and to diminish the weight of the requested cognitive resources. We told them that there were no right and wrong answers, and that it was important that each child respond sincerely. In a first session, we presented the first 
task, i.e., a written definition task. We gave to the students a printed questionnaire in which they had to define earthquakes. We allowed them all the time that they needed to complete the task; on the whole, they used a maximum of five minutes. The questionnaire also included other tasks not analyzed here. In a second session, we administered the second task, which was an online recognition task. We gave to each student a tablet with a wireless Internet connection. The completion of the second task took about $15 \mathrm{~min}$. At the end, we thanked all the children for their participation, underlining that their answers could be useful to help children to cope with traumatic events such as earthquakes.

Before beginning the data collection, we had administered the tasks to two children of the same age range of our sample, to check their feasibility.

Concerning parents, when completing the informed consent form, they also completed a questionnaire on sociodemographic data and children's experience of earthquakes.

\subsection{Materials and Coding}

\subsubsection{Written Definition Task}

In the written definition task, we asked children to write what an earthquake is (e.g., What is an earthquake? Write all the things that come to mind to explain to a child what an earthquake is; in Italian: Che cos'è un terremoto? Scrivi tutto quello che ti viene in mente per spiegare a un/a bambino/a che cos'è un terremoto). We adapted the task from previous studies, e.g., [26,31].

We transcribed verbatim all the definitions and coded them for their complexity, in terms of content type, adapting previous coding schemes [26,30,31,63]. We coded the absence/presence (0/1) of contents regarding material (natural and man-made) and person-related domain, e.g., [26]. Contents were defined as phenomena in terms of entities but also related processes. As in previous research [26], the coding scheme was developed deductively integrating categories from the literature [24-27] and inductively on the bases of the contents within children's definitions [64]. Natural elements pertained to earthquakes' geological characteristics (e.g., When the earth moves; It is a huge fissure; An earthquake is a shake which provokes landslides and fissures in the terrain; in Italian: Quando la terra si muove; è una crepa gigante; Un terremoto è una scossa che provoca frane e crepe nel terreno). Man-made elements related to all things that were built by people (e.g., It makes all the things at home swing; The earthquake is a thing that shakes the houses and destroys the houses; The earthquake is a thing that makes things move; in Italian: Fa dondolare tutte le cose a casa; Il terremoto è una cosa che fa tremare le case e distrugge le case; Il terremoto è una cosa che fa muovere le cose). Person-related elements included all aspects pertaining to three categories, namely people's behaviors, and excluded those related to building things (behavioral aspects; e.g., To protect you from an earthquake you have to go under the table; When it comes, you have to get under something; Children go out and they write their names [... ] so the teacher is sure that all the children are there and there aren't children who have fallen behind; in Italian: Per salvarsi dal terremoto andare sotto il tavolo; Quando viene devi andare sotto qualcosa; I bambini vanno fuori e scrivono i loro nomi [ ... ] così la maestra è sicura che $i$ bambini siano completi e non ci sono bambini che sono rimasti indietro); people's body, in terms of biological domain, and including reference to deaths and injuries (biological aspects; e.g., The earthquake can cause many injuries but also many dead people; Pieces of wall can fall on your head; Something that [ ... ] kills people and animals; in Italian: Il terremoto può causare molti feriti ma anche molti morti; Ti possono cadere dei pezzi di muro in testa; Una roba che [ ... ] uccide persone e animali); and affect, referring to emotions, mood, feelings, and also mental health symptoms (affective aspects; e.g., It is not a good thing; An earthquake frightens everyone; It causes much panic to people, but you have to stay calm because the panic provokes fear and distress and other things; in Italian: Non è una roba bella; Un terremoto fa venire paura a tutti; Fa molto panico alle persone ma bisogna stare calmi perché il panico provoca paura e disagio e altre cose).

A first judge coded all the definitions, while a second judge coded $30 \%$ of them for reliability. The mean percentage agreement was $95 \%$ for natural domain, $98 \%$ for man-made domain, and $100 \%$ for person-related domain. Disagreements were solved through discussion between judges. 


\subsubsection{Online Recognition Task}

In the online recognition task, we asked the children to evaluate how much different graphic stimuli are representative of an earthquake. The task had previously been used with adult participants [65]. For completing the task, each child used a tablet in which we had set the link to an online survey, functioning through a common Internet browser. The survey was developed and administered using the Cognitive Metrix Survey Software, CMSS [54,66], a customization of the LimeSurvey open-source project [67].

The graphic stimuli were drawings developed ad-hoc to refer to the different elements of earthquakes that had resulted in be salient in children's representation [26]. We had an illustrator create a total set of 16 drawings (Table 1). All the drawings for the online recognition task had to include at least one element directly pertaining to the earthquake, and we chose to represent elements indicating shaking of the environment (see the red signs in Table 1). The environment was formed only by natural elements for half of them (i.e., flat ground with a fissure; a mountain with a fissure and rocks falling) and also by man-made elements for the other half (i.e., a house with a fissure and tiles falling; a bridge with a fissure). Each set of images could vary for the different presence of person-related elements, given that we were interested in studying experimentally how the different presence of person-related elements could differently influence children's representation, isolating the effect of the different characteristics of human beings. We therefore set four experimental conditions for person-related elements. Again, we chose categories of person-related elements spontaneously reported by children defining earthquakes [26]. Person-related elements could be absent, they could refer to a behavioral reaction (i.e., a stylized person who is escaping), to biological damage (i.e., a stylized person with bandages), or to an emotional reaction (i.e., a scared face). It is worth noting that previous research confirmed that for both children and adults fear is the most salient emotion associated with earthquakes $[26,68]$. We did not include combinations of the three person-related elements (e.g., biological damage and emotional reaction in the same drawing) because the number of stimuli would have been too high, in relation to children's attention abilities.

Table 1. Graphic stimuli developed for the study, varying for natural vs. man-made elements, and for person-related elements (absent, behavioral, biological, affective).

\begin{tabular}{llllll}
\hline Person-Related Elements & Absent & Behavioral & Biological & Affective \\
Natural elements & &
\end{tabular}

The respondents were presented with the 16 drawings, and for each one we asked them to evaluate the degree to which it was representative of an earthquake (e.g., How much does this drawing make you think of an earthquake?; in Italian: Quanto questa figura ti fa pensare a un terremoto?) on a 5-point Likert type scale $(1=$ not at all, $5=$ very $m u c h)$. We randomized the order of presentation of the images. We read aloud all the questions in order to favor children's understanding of the task.

\subsubsection{Sociodemographic Data and Experience of Earthquakes}

In a written questionnaire for parents, we asked children's date of birth, gender, and family socioeconomic status (in terms of information on parents' instruction and job).

We also investigated children's experience of earthquakes, asking to the parents: (a) whether their children had ever experienced an earthquake $(0=n o, 1=y e s)$; (b) in cases where it had happened, how many times it had happened; (c) in cases where it had happened, what kind of damage they had 
experienced $(1=$ no damage $; 2=$ damage to properties $; 3=$ psychological damage to relatives; $4=$ physical damage to relatives; $5=$ death of relatives; $6=$ psychological damage to oneself; $7=$ physical damage to oneself $)$.

\subsection{Data Analysis}

First, we applied Generalized Linear Mixed Models (GLMM), as implemented in the glmer functions in the lme4 package [69] within the R-software (Version 3.6.0, R Core Team, Wien, Austria) [70], to explore the salience of different content types, and the influence of class level (second, fourth-graders) and gender (males, females) on responses (objectives 1a, 1b, and 2b). We performed Mixed Model ANOVA Tables (Type 3 tests) via likelihood ratio tests implemented in the afex package of the R-software [71-74]; for applications see, for example, [32,75-81]. For the various analyses, class level and gender were the between-subject factors; content types were the within-subject factors. For binary dependent variables, the GLMM used the binomial family and logit link-function; in the case of count dependent variables, the GLMM used the Poisson family and logarithmic link-function (log link-function). For binary dependent variables, descriptive statistics reported in the text refer to logit-scale, which is a scale in which the unit of measurement is based on the log of the probability of occurrence of an event divided by the probability of non-occurrence of the same event. For example, when both probabilities are $50 \%$, the logit value is equal to zero; when the probability of occurrence is higher than the probability of non-occurrence, the logit value is positive; and when the probability of occurrence is lower than the probability of non-occurrence, the logit value is negative. We conducted post hoc tests on the significant results using the Bonferroni correction implemented in the emmeans package [82]; this adjustment method makes it possible to deal with Type I errors by multiplying the $p$-values by the number of comparisons. We also reported the estimates (EST) as a measure of effect size [83]. The estimates corresponded to log odds ratios for binary dependent variables, and to log rate ratios for count dependent variables [82]. Given that estimates are log values, for positive estimates, the effect size is small when $0.00<E S T \leq 0.50$, medium when $0.50<E S T \leq 1.00$, and large when $E S T>$ 1.00; for negative estimates, effect size is small when $0.00>E S T \geq-0.50$, medium when $-0.50>E S T \geq$ -1.00 , and large when EST $<-1.00$ [84]. The level of significance was $p<0.05$.

Second, we applied the Rasch model [35,41-43] to quantify how much each drawing conveyed the concept of earthquake (objective 2a). The Rasch analysis was carried out using the RUMM2030 software (Version 5.1, RUMM Laboratory, Perth, Australia) [85,86]. First, we checked the Rasch model assumptions: monotonicity [87,88]; local independence [87,89]; unidimensionality [87,88,90]; absence of differential item (i.e., stimulus for our case) functioning (DIF) or stimulus bias $[87,88,91,92]$. Then, we considered the reliability in terms of the Person Separation Index (PSI) and the Cronbach's alpha [88,93-95]. Both indexes make it possible to examine the consistency of the responses. Nevertheless, the two indexes differ for different aspects: (a) the Cronbach's alpha can be calculated with complete data only, while the PSI can also be calculated when there are random missing data; (b) the Cronbach's alpha is calculated on the raw scores, while the PSI is based on the estimated locations of the persons, which are non-linear transformation of the raw scores. We also checked the model fit. Finally, targeting-which indicates how well the measurement range of the scale matches the distribution of the calibrating sample $[88,93,96]$ —is expressed here as floor and ceiling effects and targeting index [96].

There were no missing answers.

\section{Results}

\subsection{Written Definition Task (Objectives 1a and 1b)}

\section{Definitions' Content Types: Salience, Age, and Gender Differences}

First, we carried out a preliminary analysis to compare the three person-related content types. We included person-related elements (behavioral, biological, and affective elements) as the fixed effect; 
participants as the random effect; and person-related elements scores as binary dependent variables. No significant effects emerged.

Second, we ran a GLMM with content type (natural, man-made, and person-related), class level, and gender as fixed effects; participants as the random effect; and content type scores as binary dependent variables. We found a significant effect of content type, $\chi^{2}(2)=58.15, p<0.001$. Post hoc tests indicated that the scores were significantly higher, $z=5.34, p<0.001, E S T=1.82$, for natural elements $(M=0.78, S D=0.26,95 \%$ CI: 0.73 to 0.82$)$ compared to man-made elements $(M=0.37, S D=$ $0.29,95 \%$ CI: 0.32 to 0.42 ), and in turn significantly higher, $z=4.38, p<0.001, E S T=1.54$, for man-made elements compared to person-related elements $(M=0.11, S D=0.20,95 \% \mathrm{CI}$ : 0.08 to 0.15$)$. No class level or gender differences emerged. See Figure 1 for response rates relating to content types (natural, man-made, and person-related) expressed in logit-scale.

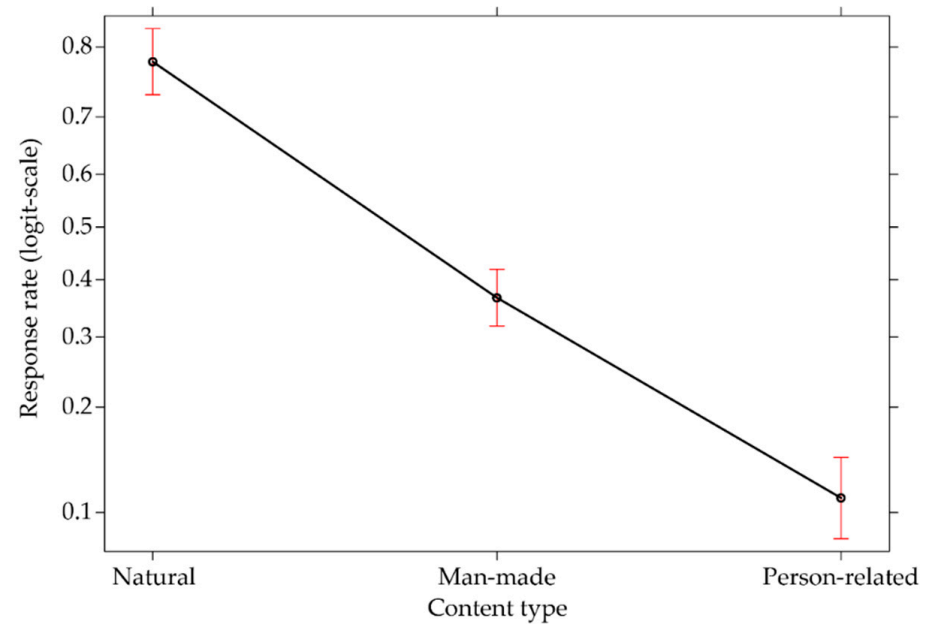

Figure 1. Response rates relating to content types (natural, man-made, and person-related) expressed in logit-scale.

\subsection{Online Recognition Task (Objectives $2 a$ and $2 b$ )}

\subsubsection{Rasch Model: Scaling of Drawings}

Concerning the Rasch model assumptions, the monotonicity request was satisfied, i.e., the responses for all the stimuli were used consistently (the difficulty thresholds were ordered) [97]. There was no local dependence: For all the stimuli, the residual correlations were lower than 0.2 [89]. The unidimensionality was confirmed by a post hoc paired $t$-test on separate estimates for each respondent (derived from subsets of stimuli identified by a Principal Component Analysis of the residuals): The percentage of significant tests was less than $5 \%$ of all the tests [90]. Lastly, no DIF was found [91], tested by a two-way analysis of variance for each stimulus, comparing scores across each level of person factor (gender and class level).

With regard to the model fit for the individual stimulus and the person level, each residual was in the range between $-/+2.5$. The summary fit residual statistics were expected to approach a mean of zero and a standard deviation of 1 [91]. Precisely, the summary residual statistics calculated values for stimuli were 0.185 (mean) and 0.713 (standard deviation). For persons, they were -0.264 (mean) and 1.587 (standard deviation).

The analysis of reliability for the total sample showed a PSI value equal to 0.895 (above 0.85 as the minimum requirement for individual person measurement) [98] and a Cronbach's alpha of 0.918, suggesting consistency in the children's responses.

The targeting of the scale to the sample shows graphically how well individual stimulus difficulties and individual person abilities can be matched on common scale [41]. The average person ability and standard deviation indicate how well the scale is targeted to the sample [88,92]. Analysis of targeting 
also entails the assessment of floor and ceiling effects. Figure 2 shows that the overall targeting was very good. The difference between average person ability and average stimulus difficulty was equal to 0.726 , namely the persons were a little more skilled than stimulus difficulty.

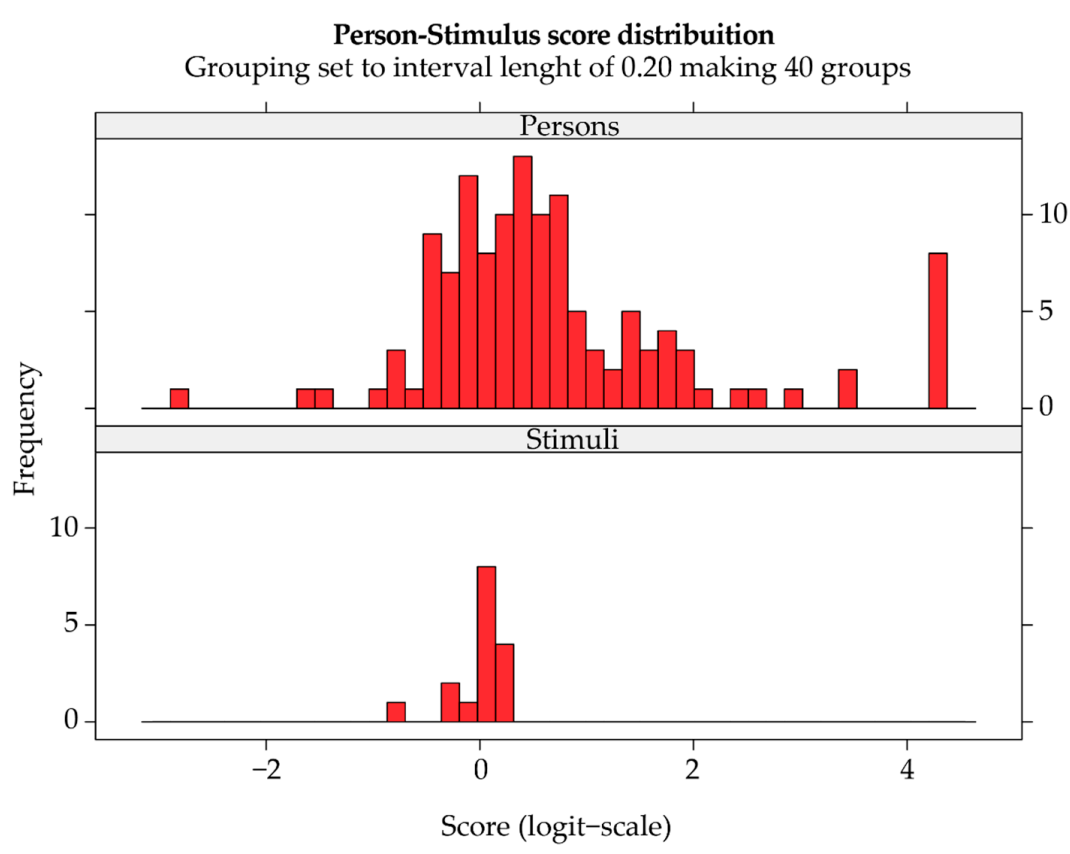

Figure 2. The upper bars represent groups of persons with the same total score; the lower bars represent groups of stimuli with the same total score. Between the two graphs, the logit scale is represented. In this kind of graph, the average stimulus score is always set at 0.0 logits. Overall, the targeting is very good, as there is a good matching between person-scores and stimulus-scores.

See Figure 3 for the representation of the scaling of the stimuli along one dimension, according to how much they convey the concept of earthquake, grouped by content type.

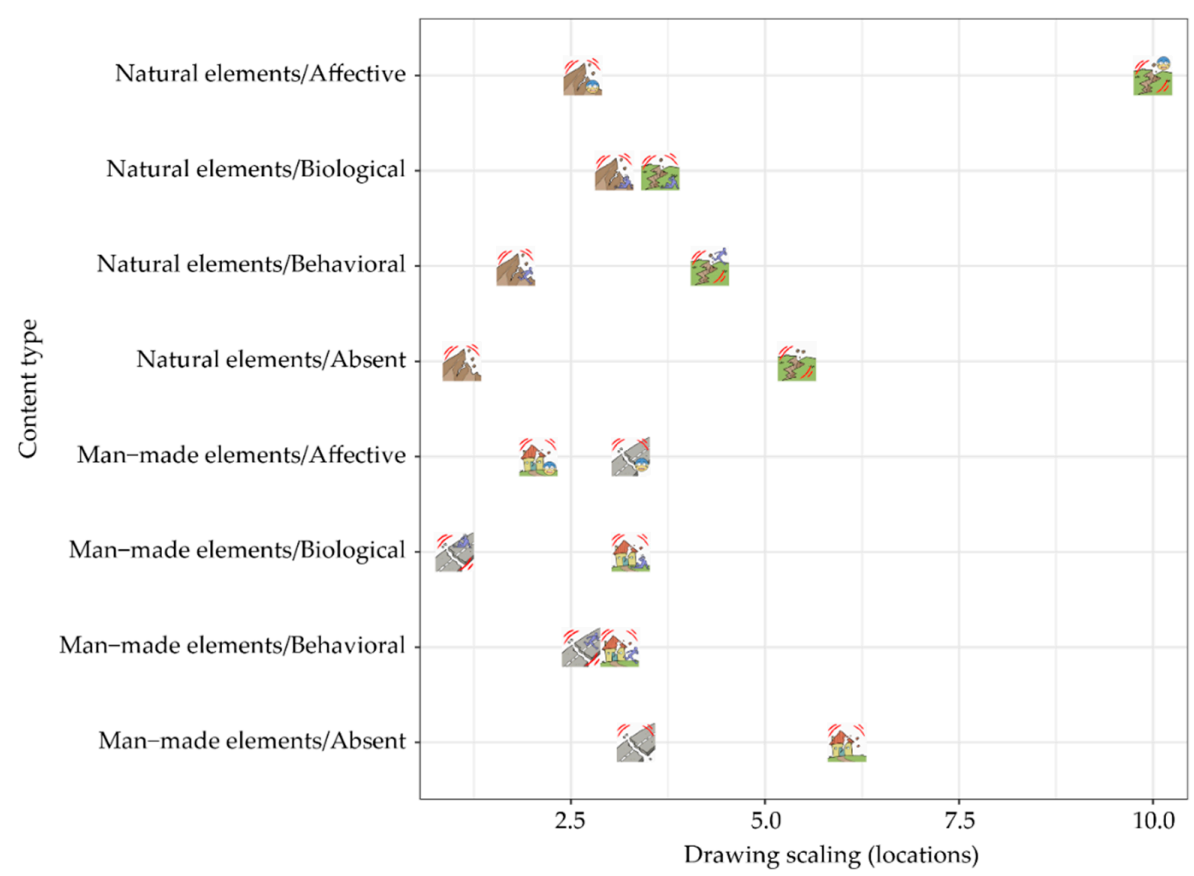

Figure 3. Scaling of the stimuli along one dimension, according to how much they convey the concept of earthquake, grouped by content type. 
It is worth noting that the drawing perceived as the most representative of an earthquake was the one depicting a fissure in the plain terrain, in which we had added the scared face. This finding confirmed the salience of natural versus built elements in children's representation of earthquakes. In addition, it suggests that children differentiate secondary effects of earthquakes, i.e., landslides, from primary effects, and consider the first more peripheral in their representation of earthquakes. Finally, we underline that fear is the person-related element which mostly characterizes children's representation.

\subsubsection{Drawings: Age and Gender Differences}

Finally, we conducted a GLMM with class level (second- and fourth-graders) and gender as the fixed effects; participants as the random effect; and the person-locations as calculated through the Rasch model for each participant as the count dependent variable. The analysis yielded a significant effect of class level, $F(1)=5.37, p=0.022$. Scores were higher for fourth $(M=64.055, S D=16.142$, $95 \%$ CI $[60.547,67.562])$ compared to second-graders $(M=58.266, S D=11.691,95 \%$ CI $[54.787,61.745])$. No gender differences emerged.

\section{Discussion and Conclusions}

Acknowledging the relevance of prevention programs for fostering preparedness to natural disasters [1], we investigated children's representation of earthquakes with different tasks.

The literature on children's psychological development demonstrated that children already possess quite a large "toolbox" for understanding the nature of the physical, biological, and psychological phenomena and their interrelations [12-16]. Such knowledge can be considered as a prerequisite in order to acquire and refine knowledge of earthquakes. Supporting and extending previous studies [24-27], our findings indicated that on the whole knowledge and representation of earthquakes involve both natural and geological characteristics, as well as people-related characteristics. Such categories include all the elements pertaining to the things that are built by humans, but also all those elements relating to their functioning, in terms of behavioral, biological, and affective domain.

From the analyses of the definitions, it emerged that, in children's representation of earthquakes, natural elements such as geological ones are the most salient, followed by man-made elements, and in turn by person-related elements, extending and generalizing previous findings with oral definition tasks [26]. Therefore, Italian primary school children possess a basic knowledge of earthquakes, differentiating elements pertaining to different domains, and giving particular relevance to the core geological issues characterizing earthquakes. At the same time, they have an initial awareness of the different elements to which damage can be associated, reporting more frequently macroscopic and external consequences for the structures which are built by the individuals, but without neglecting the consequences for humans. Specifically, behaviors such as escaping, biological consequences such as being hurt, or affective reactions assume all a similar relevance.

Data from the recognition task supported these findings. First, we examined how much each drawing conveyed the idea of earthquake. To achieve this goal, we analyzed the scores given to the different exemplars of our set of drawings, which included natural or built elements combined with the four experimental conditions relating to person-related elements, that could be absent, behavioral, biological, or affective. Quantifying, through scientific approaches which respect the properties of the fundamental measurement (i.e., the Rasch model) [42,44,45,51], how much the different stimuli conveyed the concept of earthquake could be a first step for the development of specific scales for assessing people's perception of natural disasters such as earthquakes. Second, we found that the drawing that conveyed most the idea of earthquake was the one that included natural but not built elements. Among the two possible images, the most representative was specifically the one representing the fissure in the ground, and not the landslide, suggesting children's ability to identify the core characteristic of earthquakes as distinguished by their secondary effects. In addition, we highlight that the most representative image also included emotional elements, indicating that children 
already grasp the somehow overwhelming emotional burden associated with disasters. This element could be interpreted as a sign of the relevance of planning prevention programs focused on emotional prevention specifically devoted to developing children's understanding of earthquake-related emotions and regulation strategies, an issue currently still neglected [28]. For an exception, see the PrEmT project [28]. It is worth noting that providing pre-drawn representations and using ICT allows for a larger sample and the use of a range of statistical tools, but it does not make it possible to give value to the rich abilities already possessed by primary school children to represent the world. We could state that this particular activity investigated how well children connected with adult representations rather than only revealing how they represented the events themselves.

As regards age differences in children's representation of earthquakes, the analyses reported in our study only partially revealed them. Concerning written definitions, our results did not reveal age differences, differently from Raccanello and colleagues' study [26], who found that, in oral definitions of earthquakes, older children reported more information compared to younger children. It could be that the distance in terms of competence (i.e., for producing written definitions) between the younger and the older children is presumably higher for oral tasks than for written tasks. However, in Raccanello and colleagues' study [26], second-graders were compared to fifth-graders, and so the different age range for our sample (i.e., two years instead of three years) could have been related to the absence of this effect. Nevertheless, examining the means for the sample of second and fourth-graders included in our study, we can note that the difference among them is in the expected direction, with older students reporting a higher variety of contents (even if the difference between them was not statistically significant). Moreover, it is interesting to note that the recognition task was somehow more sensitive to age differences compared to the production task, given that through such task we detected age differences in the expected direction. At increasing ages, children were better able to interpret a given stimulus as conveying the concept of earthquake. In other words, older children demonstrated a more refined ability to identify images relating to earthquakes (all of them included a fissure and shaking of the ground) as conveying the intended meaning. Empirical evidence relating to the development of this ability at increasing ages can result very useful. For example, knowledge of which elements of earthquakes' representation are salient at different ages can be considered in order to develop instruments to be used as alert signals for emergency situations.

From an applied perspective, it is very important to develop instruments for identifying the naïve ideas of children on the entities and functioning of the physical, biological, and psychological world for maximizing the possibility of success of interventions focused on them. In school contexts, it is central to detect possible wrong ideas included in children's naïve theories as soon as possible, in order to discard them and increase the possibility that formal instruction is associated with learning outcomes which last over time [99]. To guarantee the efficacy of science education, it is highly relevant that students acknowledge their intuitive ideas, that teachers give them scientific facts and explanations in accordance with their level of cognitive development taking into account their naïve understandings, and that this process unfolds along with the promotion of critical thinking and reasoning abilities [99]. Similarly, within prevention programs aiming at increasing children's knowledge of earthquakes, possible wrong ideas included in their spontaneous representations of earthquakes should be detected early, in order to increase the success of such programs in ameliorating children's learning both at short-term and at long-term. Therefore, identifying instruments helping to describe accurately children's representation is a key step for the development of prevention programs aiming to enhance preparedness to disasters.

Schools play a central role also in the aftermath of natural disasters such as earthquakes, as revealed in studies conducted in a country that has experienced multiple earthquakes in more recent years, New Zealand [100]. For example, Bateman and Dandy [101] described a case study with four preschoolers who talked with their teachers about their experiences of the 2011 Christchurch earthquake; they analyzed turn-taking utterances and revealed that such practice can help to recover from the emotional stress associated with earthquakes and prevent from further stress. Mutch and Gawith [102] described 
three different ways through which schools helped children to come to terms with their experiences of several earthquakes (always in Christchurch) within a UNESCO-funded project: In one school children, parents, and teachers wrote an illustrated book together; in a second school they created a mosaic story on antecedents, core, and aftermath of the earthquakes; and in a third school they conducted interviews about the earthquakes. Lessons learnt from how children narrate and reconstruct the meaning of what they experienced, developing shared memories within a community, can give useful suggestions also from a prevention perspective. Based on the findings of these studies [100-102], we could argue that story-telling, both individual and collective, can be a useful methodology to help children and significant adults to build the meaning of experiences, also before a disaster happens. Such a tool enables both to build factual appropriate knowledge, and to help to reflect on the emotional nuances of how natural disasters can impact children's life, in an attempt to give them the resources to "gain perspective and distance" within their coping processes (p. 54) [102].

When reflecting on the methodological gain of our findings, we could argue that both production and recognition tasks, operationalized though oral, written, or online instruments (see Raccanello and colleagues [26] for oral production tasks, i.e., definition task; see this paper for written production tasks, i.e., definition task, and online recognition tasks) are reliable methodologies enabling to gather knowledge of children's representations on earthquakes. We already anticipated that, generally, production and recognition tasks differ in terms of the cognitive resources requested to master them. In addition, production tasks including open-ended questions and recognition tasks in terms of closed-ended questions differently enable to shed light on the different nuances with which the individuals perceive, elaborate, and represent reality, more differentiated and richer for the first compared to the latter, e.g., [30-33]. However, data gathered through tasks such as the online recognition task that we used have the possibility to be treated with analyses models, i.e., the Rasch models [35-40], which go beyond the typical limitations of the traditional measurement approaches, with advantages in terms of the quality of the assessed representation. Finally, the three methodologies have different constraints in terms of managing time and number of people which can be involved simultaneously. Oral production tasks are the most time-consuming, followed by written production tasks, and finally by online recognition tasks. To study individual differences, oral tasks should be administered individually, while written and online tasks can be administered also collectively.

Beyond these general strengths and limitations, the different tasks can be examined specifically focusing on how they helped to detect and describe children's representation of earthquakes. On the one hand, the salience of the different domains was basically confirmed across the three tasks. Our analyses of the contents of oral definitions supported previous findings with oral definition tasks [26] and extended them. Therefore, the three different tasks can be considered reliable in reaching their basic goals. On the other hand, age differences were not so well detected by a task requiring the use of writing abilities, compared to the recognition task. Particularly the latter, beyond requiring a lower amount of cognitive resources, could also take advantage of many of the benefits of using ICT [28,58], included the higher attractiveness particularly motivating for children.

On the whole, our findings suggest that when planning the specific methodology to be used in a prevention program, but also in a support intervention with children, scientists and practitioners should be particularly cautious in their choices, reflecting on and balancing both benefits and disadvantages in utilizing different instruments.

Our study suffers from limitations related to the nature of the instruments used, as already described. Moreover, there are also other useful methodologies to examine children's representation of earthquakes, such as analyzing drawings, that we did not use. Such instruments could be utilized in future research. There are specific limitations relating to the tasks that we developed. For example, for the online recognition task we did not consider all the possible combinations between the elements at issue, e.g., representing biological and affective damage in the same drawing. Future studies could examine more deeply the salience of many combinations of elements pertaining to different domains for children's representation of earthquakes. In addition, it is worth noting that we involved only 
a small sample of primary school students, and only in relation to earthquakes. Future research could verify whether our findings extend to younger children, but also to adolescents, adults, and elderly people, in order to examine more thoroughly how the representation of earthquakes changes with development. In addition, children in our sample rarely experienced directly earthquakes, and when they had experienced them, they luckily had not suffered from personal damage. Further studies could take into account more deeply the role of personal exposure, comparing samples who for example experienced directly, indirectly, or did not experience at all earthquakes. Finally, it would be highly relevant to extend the study of individuals' representations of phenomena such as earthquakes to a larger range of disasters, examining both natural and technological disasters, as a step to support awareness on citizens' resources for developing disaster-resilient societies.

Author Contributions: Conceptualization, D.R. and R.B.; methodology, D.R., G.V. and R.B.; software, G.V. and R.B.; formal analysis, R.B.; investigation, D.R., G.V. and R.B.; data curation, D.R., G.V. and R.B.; writing-original draft preparation, D.R., G.V., and R.B.; writing-review and editing, D.R.; visualization, R.B.; supervision, D.R.; project administration, D.R.; funding acquisition, D.R. and R.B.

Funding: This work was supported by the Fondazione Cariverona, Bando Ricerca Scientifica 2017, Italia.

Acknowledgments: The authors would like to thank all the participants and the teachers of the involved schools. They also would like to thank Veronica Barnaba, Erminia Dal Corso, Emmanuela Rocca, Giulia Rosolen, and Lorenza Marchiori for their help in the project. They finally thank Elisa Ferrari for drawing the images.

Conflicts of Interest: The authors declare no conflict of interest. The funders had no role in the design of the study; in the collection, analyses, or interpretation of data; in the writing of the manuscript, or in the decision to publish the results.

\section{References}

1. Scolobig, A.; De Marchi, B.; Borga, M. The missing link between flood risk awareness and preparedness: Findings from case studies in an Alpine Region. Nat. Hazards 2012, 63, 499-520. [CrossRef]

2. INGV, Istituto Nazionale di Geofisica e Vulcanologia [National Institute of Geophysics and Volcanology]. Available online: www.ingvterremoti.wordpress.com (accessed on 24 February 2019).

3. Shoshani, A.; Slone, M. The drama of media coverage of terrorism: Emotional and attitudinal impact of the audience. Stud. Confl. Terror. 2008, 31, 627-640. [CrossRef]

4. Fergusson, D.M.; Boden, J.M. The psychological impacts of major disasters. Aust. N. Z. J. Psychiatry 2014, 48, 597-599. [CrossRef]

5. Galambos, C.M. Natural disasters: Health and mental health considerations. Health. Soc. Work 2005, 30, 83-86. [CrossRef]

6. Neria, Y.; Nandi, A.; Galea, S. Post-traumatic stress disorder following disasters: A systematic review. Psychol. Med. 2008, 38, 467-480. [CrossRef]

7. Ben-Zur, H.; Gil, S.; Shamshins, Y. The relationship between exposure to terror through the media, coping strategies and resources, and distress and secondary traumatization. Int. J. Stress Manag. 2012, 19, 132-150. [CrossRef]

8. Furr, J.M.; Comer, J.S.; Edmunds, J.M.; Kendall, P.C. Disasters and youth: A meta-analytic examination of posttraumatic stress. J. Consult. Clin. Psychol. 2010, 78, 765-780. [CrossRef] [PubMed]

9. Masten, A.S.; Osofsky, J.D. Disasters and their impact on child development: Introduction to the special section. Child. Dev. 2010, 81, 1029-1039. [CrossRef]

10. Raccanello, D.; Burro, R.; Brondino, M.; Pasini, M. Relevance of terrorism for Italian students not directly exposed to it: The affective impact of the 2015 Paris and the 2016 Brussels attacks. Stress Health 2018, 34, 338-343. [CrossRef] [PubMed]

11. Kar, N. Psychological impact of disasters on children: Review of assessment and interventions. World J. Pediatr. 2009, 5, 5-11. [CrossRef] [PubMed]

12. Allen, M. Preschool children's taxonomic knowledge of animal species. J. Res. Sci. Teach. 2015, 52, 107-134. [CrossRef]

13. Schulz, L.E.; Gopnik, A. Causal learning across domains. Dev. Psychol. 2004, 40, 162-176. [CrossRef] [PubMed] 
14. Wellman, H.M.; Gelman, S.A. Cognitive development: Foundational theories of core domains. Annu. Rev. Psychol. 1992, 43, 337-375. [CrossRef]

15. Wellman, H.M.; Inagaki, K.E. (Eds.) The Emergence of Core Domains of Thought: Children's Reasoning about Physical, Psychological, and Biological Phenomena; Jossey-Bass: San Francisco, CA, USA, 1997.

16. Zhu, L.; Liu, G. Preschool children's understanding of illness. Acta Psychol. Sin. 2007, 39, 96-103.

17. Carey, S. On the origin of causal understanding. In Causal Cognition: A Multidisciplinary Debate; Sperber, D., Premack, D., Premack, A.J., Eds.; Clarendon Press: Oxford, UK, 1995; pp. 268-302.

18. Inagaki, K.; Hatano, G. Children's understanding of mind-body relationships. In Children's Understanding of Biology and Health; Siegal, M., Peterson, C.C., Eds.; Cambridge University Press: Cambridge, UK, 1999; pp. 23-44.

19. Siegal, M.; Peterson, C.C. (Eds.) Children's Understanding of Biology and Health; Cambridge University Press: Cambridge, UK, 1999.

20. Hughes, C.; Leekam, S. What are the links between theory of mind and social relations? Review, reflections and new directions for studies of typical and atypical development. Soc. Dev. 2004, 13, 590-619. [CrossRef]

21. Wellman, H.M. The Child's Theory of Mind; Bradford Books/MIT Press: Cambridge, MA, USA, 1990.

22. Brown, J.; Dunn, J. Continuities in emotion understanding from three to six years. Child Dev. 1996, 67, 789-802. [CrossRef]

23. Wimmer, H.; Perner, J. Beliefs about beliefs: Representation and constraining function of wrong beliefs in young children's understanding of deception. Cognition 1983, 13, 103-128. [CrossRef]

24. King, T.A.; Tarrant, R.A.C. Children's knowledge, cognitions and emotions surrounding natural disasters: An investigation of Year 5 students, Wellington, New Zealand. AJDTS 2013, 1, 17-26.

25. Laçin Şimşek, C. Children's ideas about earthquakes. Int. J. Environ. Sci. Educ. 2007, 2, 14-19.

26. Raccanello, D.; Burro, R.; Hall, R. Children's emotional experience two years after an earthquake: An exploration of knowledge of earthquakes and associated emotions. PLoS ONE 2017, 12, e0189633. [CrossRef]

27. Ross, K.E.; Shuell, T.J. Children's beliefs about earthquakes. Sci. Educ. 1993, 77, 191-205. [CrossRef]

28. Raccanello, D.; Vicentini, G.; Brondino, M.; Burro, R. Technology-based trainings on emotions: A web application on earthquake-related emotional prevention with children. In International Conference in Methodologies and Intelligent Systems for Technology Enhanced Learning; Springer: Cham, Switzerland, in press.

29. Pekrun, R.; Bühner, M. Self-report measures of academic emotions. In International Handbook of Emotions in Education; Pekrun, R., Linnenbrink-Garcia, L., Eds.; Taylor \& Francis: New York, NY, USA, 2014; pp. 561-579.

30. Gobbo, C.; Raccanello, D. Personal narratives about states of suffering and wellbeing: Children's conceptualization in terms of physical and psychological domain. Appl. Cogn. Psychol. 2011, 25, 386-394. [CrossRef]

31. Raccanello, D. L'adozione dal punto di vista dei bambini: Ruolo di età e coinvolgimento personale [Adoption from children's point of view: Role of age and personal involvement]. Psic. Clin. Svil. 2012, 16, 507-529.

32. Raccanello, D.; Hall, R.; Burro, R. Salience of primary and secondary school students' achievement emotions and perceived antecedents: Interviews on literacy and mathematics domains. Learn. Individ. Differ. 2018, 65, 65-79. [CrossRef]

33. Shaughnessy, J.J.; Zechmeister, E.B.; Zechmeister, J.S. Research Methods in Psychology; McGraw-Hill: New York, NY, USA, 2012.

34. Otto, B.W. Language Development in Early Childhood Education, 3rd ed.; Pearson: Boston, MA, USA, 2010.

35. Burro, R. To be objective in experimental phenomenology: A psychophysics application. Springerplus 2016, 5, 1720. [CrossRef] [PubMed]

36. Chimi, C.J.; Russell, D.L. The Likert scale: A proposal for improvement using quasi-continuous variables. In Proceedings of the ISECON, Washington, DC, USA, 5-8 November 2009.

37. Henson, R.K.; Hull, D.M.; Williams, C.S. Methodology in our education research culture. Educ. Res. 2010, 39, 229-240. [CrossRef]

38. Harwell, M.R.; Gatti, G.G. Rescaling ordinal data to interval data in educational research. Rev. Educ. Res. 2001, 71, 105-131. [CrossRef]

39. Jamieson, S. Likert scales: How to (ab)use them. Med. Educ. 2004, 38, 1212-1218. [CrossRef] [PubMed]

40. Knapp, T.R. Treating ordinal scales as interval scales: An attempt to resolve the controversy. Nurs. Res. 1990, 39, 121-123. [CrossRef]

41. Andrich, D. Rasch Models for Measurement; Sage Publications: Beverly Hills, LA, USA, 1988. 
42. Bond, T.G.; Fox, C.M. Applying the Rasch Model: Fundamental Measurement in the Human Sciences, 2nd ed.; Includes Rasch software on CD-ROM; Lawrence Erlbaum Associates: Mahwah, NJ, USA, 2007.

43. Rasch, G. Probabilistic Models for Some Intelligence and Attainment Tests; Copenhagen, Danish Institute for Educational Research, expanded edition (1980) with foreword and afterword by B.D. Wright; The University of Chicago Press: Chicago, IL, USA, 1980.

44. Luce, R.D.; Krantz, D.H.; Suppes, P.; Tversky, A. Foundations of Measurement; Academic: San Diego, CA, USA, 1990; Volume 3.

45. Cavanagh, R.F.; Romanoski, J.T. Rating scale instruments and measurement. Learn. Environ. Res. 2007, 9, 273-289. [CrossRef]

46. Bianchi, I.; Savardi, U.; Burro, R. Perceptual ratings of opposite spatial properties: Do they lie on the same dimension? Acta Psychol. 2011, 138, 405-418. [CrossRef]

47. Burro, R.; Pasini, M.; Raccanello, D. Using Rasch Models for developing fast technology enhanced learning solutions: An example with emojis. In International Conference in Methodologies and Intelligent Systems for Technology Enhanced Learning; Springer: Cham, Switzerland, in press.

48. Burro, R.; Pasini, M.; Raccanello, D. Emojis' psychophysics: Measuring emotions in technology enhanced learning contexts. In International Conference in Methodologies and Intelligent Systems for Techhnology Enhanced Learning; Springer: Cham, Switzerland, 2019; Volume 804, pp. 70-78.

49. Burro, R.; Sartori, R.; Vidotto, G. The method of constant stimuli with three rating categories and the use of Rasch models. Qual. Quant. 2011, 45, 43-58. [CrossRef]

50. Burro, R.; Savardi, U.; Annunziata, M.A.; De Paoli, P.; Bianchi, I. The perceived severity of a disease and the impact of the vocabulary used to convey information: Using Rasch scaling in a simulated oncological scenario. Patient Prefer Adherence 2018, 12, 2553-2573. [CrossRef]

51. Wright, B.D. Fundamental measurement for psychology. In The New Rules of Measurement: What Every Educator and Psychologist should Know; Embretson, S.E., Hershberger, S.L., Eds.; Lawrence Erlbaum Associates: Hillsdale, NJ, USA, 1999; pp. 65-104.

52. Pasini, M.; Brondino, M.; Burro, R.; Raccanello, D.; Gallo, S. The use of different multiple devices for an ecological assessment. In Methodologies and Intelligent Systems for Technology Enhanced Learning; Springer: Cham, Switzerland, 2016; Volume 478, pp. 121-129.

53. Raccanello, D.; Brondino, M.; Crane, M.; Pasini, M. Antecedents of achievement emotions: Mixed-device assessment with Italian and Australian university students. In Methodologies and Intelligent Systems for Technology Enhanced Learning; Springer: Cham, Switzerland, 2016; Volume 478, pp. 183-191.

54. Raccanello, D.; Burro, R.; Brondino, M.; Pasini, M. Use of internet and wellbeing: A mixed-device survey. In Methodologies and Intelligent Systems for Technology Enhanced Learning; Springer: Cham, Switzerland, 2017; Volume 617, pp. 65-73.

55. Toepoel, V.; Lugtig, P. Online surveys are mixed-device surveys. Issues associated with the use of different (mobile) devices in web surveys. MDA 2015, 9, 155-162. [CrossRef]

56. Kreuter, F.; Presser, S.; Tourangeau, R. Social desirability bias in CATI, IVR, and web surveys: The effects of mode and question sensitivity. Public Opin. Q. 2008, 72, 847-865. [CrossRef]

57. Bowling, A. Mode of questionnaire administration can have serious effects on data quality. J. Public Health 2005, 27, 281-291. [CrossRef]

58. Shiffman, S.; Stone, A.A.; Hufford, M.R. Ecological momentary assessment. Annu. Rev. Clin. Psychol. 2008, 4, 1-32. [CrossRef]

59. Axinn, W.; Gatny, H.; Wagner, J. Maximizing data quality using mode switching in mixed-device survey design: Nonresponse bias and models of demo-graphic behaviour. MDA 2015, 9, 163-184. [CrossRef]

60. Flay, B.R.; Biglan, A.; Boruch, R.F.; Castro, F.G.; Gottfredson, D.; Kellam, S.; Moscicki, E.K.; Schinke, S.; Valentine, J.C.; Ji, P. Standards of evidence: Criteria for efficacy, effectiveness and dissemination. Prev. Sci. 2005, 6, 151-175. [CrossRef] [PubMed]

61. Gottfredson, D.C.; Cook, T.D.; Gardner, F.E.M.; Gorman-Smith, D.; Howe, G.W.; Sandler, I.S.; Zafft, K.M. Standards of evidence for efficacy, effectiveness, and scale-up research in prevention science: Next generation. Prev. Sci. 2018, 16, 893-926. [CrossRef]

62. Raccanello, D.; Brondino, M.; Pasini, M.; Landuzzi, M.G.; Scarpanti, D.; Vicentini, G.; Massaro, M.; Burro, R. The usability. In International Conference in Methodologies and Intelligent Systems for Techhnology Enhanced Learning; Springer: Cham, Switzerland, 2019; Volume 804, pp. 79-87. 
63. Raccanello, D.; Gobbo, C. Understanding coexistence of internal states in children and adults. Eur. J. Dev. Psychol. 2015, 12, 158-176. [CrossRef]

64. Nolen, S.B. Young children's motivation to read and write: Development in social contexts. Cogn. Instruct. 2007, 25, 219-270. [CrossRef]

65. Raccanello, D.; Hall, R.; Burro, R. Formative evaluation of emojis to signal earthquake events. Unpublished work, 2019.

66. Burro, R.; Raccanello, D.; Pasini, M.; Brondino, M. An estimation of a nonlinear dynamic process using Latent Class extended Mixed Models. Affect profiles after terrorist attacks. Nonlinear Dyn. Psychol. Life Sci. 2018, 22, 35-52.

67. Schmitz, C. LimeSurvey: An Open Source Survey Tool; LimeSurvey Project: Hamburg, Germany, 2015; Available online: http://www.limesurvey.org (accessed on 19 April 2019).

68. Raccanello, D.; Barnaba, V.; Burro, R. Adults' representation of children's emotions and coping strategies related to earthquakes. In Proceedings of the 19th European Congress of Developmental Psychology, Athens, Greece, 29 August-1 September 2019.

69. Bates, D.; Maechler, M.; Bolker, B.; Walker, S. Fitting Linear Mixed-Effects Models Using lme4. J. Stat. Softw. 2015, 67, 1-48. [CrossRef]

70. R Core Team. R: A Language and Environment for Statistical Computing; R Foundation for Statistical Computing: Wien, Austria, 2019.

71. Barr, D.J. Random effects structure for testing interactions in linear mixedeffects models. Front. Psychol. 2013, 4. [CrossRef]

72. Barr, D.J.; Levy, R.; Scheepers, C.; Tily, H.J. Random effects structure for confirmatory hypothesis testing: Keep it maximal. J. Mem. Lang. 2013, 68, 255-278. [CrossRef] [PubMed]

73. Bastianello, T.; Majorano, M.; Burro, R. Children's attention in a word learning interactive context with educators and vocabulary growth. Early Child. Dev. Care 2018. [CrossRef]

74. Bates, D.; Kliegl, R.; Vasishth, S.; Baayen, H. Parsimonious Mixed Models. 2015. Available online: https://arxiv.org/pdf/1506.04967.pdf (accessed on 19 April 2019).

75. Bianchi, I.; Branchini, E.; Burro, R.; Capitani, E.; Savardi, U. Overtly prompting people to "think in opposites" supports insight problem solving. Think. Reason. 2019. [CrossRef]

76. Bianchi, I.; Canestrari, C.; Roncoroni, A.M.; Burro, R.; Branchini, E.; Savardi, U. The effects of modulating contrast in verbal irony as a cue for giftedness. Humor 2017, 30, 383-415. [CrossRef]

77. Branchini, E.; Bianchi, I.; Burro, R.; Capitani, E.; Savardi, U. Can contraries prompt intuition in insight problem solving? Front. Psychol. 2016, 7. [CrossRef]

78. Branchini, E.; Burro, R.; Bianchi, I.; Savardi, U. Contraries as an effective strategy in geometrical problem solving. Think. Reason. 2015, 21,397-430. [CrossRef]

79. Canestrari, C.; Branchini, E.; Bianchi, I.; Savardi, U.; Burro, R. Pleasures of the mind: What makes jokes and insight problems enjoyable. Front. Psychol. 2018, 8. [CrossRef] [PubMed]

80. Raccanello, D.; Gobbo, C.; Corona, L.; De Bona, G.; Hall, R.; Burro, R. Long-term intergenerational transmission of memories of the Vajont disaster. Memory in press.

81. Rigon, J.; Burro, R.; Guariglia, C.; Maini, M.; Marin, D.; Ciurli, P.; Bivona, U.; Formisano, R. Self-awareness rehabilitation after traumatic brain injury: A pilot study to compare two group therapies. Restor. Neurol. Neurosci. 2017, 35, 115-127. [CrossRef] [PubMed]

82. Lenth, R. Emmeans: Estimated Marginal Means, aka Least-Squares Means. R Package Version 1.3.3.; The University of Iowa: Iowa City, IA, USA, 2019.

83. Olivier, J.; May, W.L.; Bell, M.L. Relative effect sizes for measures of risk. Commun. Stat. Theory Methods 2017, 46, 6774-6781. [CrossRef]

84. Chen, H.; Cohen, P.; Chen, S. How big is a big odds ratio? Interpreting the magnitudes of odds ratios in epidemiological studies. Commun. Stat. Simul. Comput. 2010, 39, 860-864. [CrossRef]

85. Andrich, D.; Sheridan, B.S.; Luo, G. RUMM 2030: Rasch Unidimensional Models for Measurement; Version 5.1; RUMM Laboratory: Perth, Australia, 2010.

86. RUMM Laboratory Pty Ltd. 1997-2017. Available online: www.rummlab.com (accessed on 19 April 2019).

87. Kreiner, S. The Rasch model for dichotomous items. In Rasch Models in Health. Applied Mathematics Series; Christensen, K.B., Kreiner, S., Mesbah, M., Eds.; ISTE Ltd.: London, UK; John Wiley \& Sons, Inc.: Hoboken, NJ, USA, 2013; pp. 5-25. 
88. Tennant, A.; Conaghan, P.G. The Rasch measurement model in rheumatology: What is it and why use it? When should it be applied, and what should one look for in a Rasch paper? Arthritis Care Res. 2007, 57, 1358-1362. [CrossRef]

89. Marais, I. Local dependence. In Rasch Models in Health. Applied Mathematics Series; Christensen, K.B., Kreiner, S., Mesbah, M., Eds.; ISTE Ltd.: London, UK; John Wiley \& Sons, Inc.: Hoboken, NJ, USA, 2013; pp. 111-130.

90. Smith, E. Detecting and evaluating the impact of multidimensionality using item fit statistics and principal component analysis of residuals. J. Appl. Meas. 2002, 3, 205-231.

91. Pallant, J.F.; Tennant, A. An introduction to the Rasch measurement model: An example using the Hospital Anxiety and Depression Scale (HADS). Br. J. Clin. Psychol. 2007, 46, 1-18. [CrossRef]

92. Tennant, A.; Penta, M.; Tesio, L.; Grimby, G.; Thonnard, J.L.; Slade, A.; Lawton, G.; Simone, A.; Carter, J.; Lundgren-Nilsson, Å.; et al. Assessing and adjusting for cross-cultural validity of impairment and activity limitation scales through differential item functioning within the framework of the Rasch model: The PRO-ESOR project. Med. Care 2004, 42, I37-I48. [CrossRef]

93. Hobart, J.; Cano, S. Improving the evaluation of therapeutic interventions in multiple sclerosis: The role of new psychometric methods. Health Technol. Assess. 2009, 13, 1-177. [CrossRef] [PubMed]

94. Kreiner, S.; Christensen, K.B. Person parameter estimation and measurement in Rasch Models. In Rasch Models in Health. Applied Mathematics Series; Christensen, K.B., Kreiner, S., Mesbah, M., Eds.; ISTE Ltd.: London, UK; John Wiley \& Sons, Inc.: Hoboken, NJ, USA, 2013; pp. 63-67.

95. Wright, B.D.; Masters, G.N. Rating Scale Analysis; MESA Press: Chicago, IL, USA, 1982.

96. Fisher, W.P.J. Rating scale instrument quality criteria. RMT 2007, 21, 1095.

97. Vanhoutte, E.K.; Faber, C.G.; van Nes, S.I.; Jacobs, B.C.; van Doorn, P.A.; van Koningsveld, R.; Cornblath, D.R.; van der Kooi, A.J.; Cats, E.A.; van den Berg, L.H.; et al. Modifying the Medical Research Council grading system through Rasch analyses. Brain 2012, 135, 1639-1649. [CrossRef] [PubMed]

98. Reeve, B.B.; Hays, R.D.; Bjorner, J.B.; Cook, K.F.; Crane, P.K.; Teresi, J.A.; Thissen, D.; Revicki, D.A.; Weiss, D.J.; Hambleton, R.K.; et al. Psychometric evaluation and calibration of health-related quality of life item banks: Plans for Patient-Report Outcomes Measurement Information System (PROMIS). Med. Care 2007, 45, $22-31$. [CrossRef] [PubMed]

99. Vosniadou, S. The development of students' understanding of science. Front. Educ. 2019, 4. [CrossRef]

100. Mutch, C.; Gawith, E. The role of schools in disaster setting: Learning from the 2010-2011 New Zealand earthquakes. Int. J. Educ. Dev. 2015, 41, 283-291. [CrossRef]

101. Bateman, A.; Danby, S. Recovering from the earthquake: Early childhood teachers and children collaboratively telling stories about their experiences. Disaster Prev. Manag. 2013, 22, 467-479. [CrossRef]

102. Mutch, C.; Gawith, E. The New Zealand earthquakes and the role of schools in engaging children in emotional processing of disaster experiences. Pastor. Care Educ. 2014, 32, 54-67. [CrossRef] 